the survey no fewer than a half have onchocerciasis and that 30,000 have been blinded by it.

The author, who is the Director of the Entomological Unit of the British Empire Society for the Blind, describes in detail the distribution and the biology of the Simulium damnosum. The incidence and transmission of onchocerciasis in the fly and among humans are then dealt with and finally the possibilities of preventing and controlling the disease are discussed.

It is clear that personal repellants and detriments have only a minor role to play in the suppression of the disease and that it can only be eradicated by a widespread and costly disinfection of all the rivers and tributaries where the flies breed. It is to be hoped that money and equipment for the control scheme proposed by Dr. Crisp will be forthcoming.

J:J.T.

\section{SIR GEORGE BUCKSTON BROWNE}

By Jessie Dobson, B.A., M.Sc. Pp. viii + I42, with 28 illustrations. Edinburgh: E. \& S. Livingstone. 1957. 25s.

Like all good biographies, this volume illuminates the age as clearly as the man. Both alike were remarkable for individuality, perseverence and achievement. Buckston Browne attained a position which no longer exists under present-day policies. Cheated of the English Fellowship at the start of his career by the vindictiveness of an examiner who was jealous of his chief, he did not set foot in the college again for 20 years. When he did return it was not with rancour, but with immense generosity.

The farm in Kent is of huge value to experimental surgeons and physiologists. The dinners in London, which also bear his name, are a reminder at once of his conviviality and of his interest in many scientific societies in which he played an active part after his retirement.

He steadfastly declined to give evidence in court against any colleague.

Read and do thou likewise.

\section{CHRONIC BRONCHITIS IN NEWCASTLE UPON TYNE}

By A. G. OgIlvie, M.D., F.R.C.P., and D. J. Newell, M.A. Pp. vii + I15. Edinburgh: E. \& S. Livingstone Ltd. I957. I5s.

In the introductory chapter of this small book the unfavourable incidence of chronic bronchitis in the U.K. is well presented. Within the U.K. there are well-recognized regional variations in incidence and the survey described here is probably the first attempt to correlate the various factors which operate to produce variations in incidence within the confines of a single highly bronchitic area. A statistical assessment of the roles of smoking, asthma, working conditions, economic status, housing and atmospheric pollution as related to locality was made in this study.
Whilst advances have been made in recent years? in the treatment of chronic bronchitis and its coms plications, there can be little doubt but that the main attack on this prime cause of morbidity must be preventive in nature. This survey, and, it is to be hoped, others along similar lines which shoulde follow, will help to promote the necessary interest: in medical, social and political thought.

K.D.B.

\section{THE AUTONOMIC NERVOUS SYSTEM}

Edited by W. S. Feldberg. British Medica昂 Bulletin, Vol. 13, No. 3, September 1957. Pp. $78 \cong$ London: British Council. 1957. 20 .

The possibility exists that the autonomic nervoussystem has been both advanced in our knowledge $\vec{\omega}$ and also productive of more first-class experimentalo work than any other section of physiology in recento years. In addition, the knowledge so culled has been of greater practical application in its immediatei future to medicine and scientific understanding ${ }_{\omega}^{+}$ than perhaps any other of neurology.

This advance stems from the work of $T . R$. Elliott at Cambridge in 1904 and of Otto Loewi in r92r. From these two pioneers, very largely through Sir Henry Dale and his school at Hampstead, ino the M.R.C. Laboratories has developed the concep $\mathrm{t}^{-}$ of chemical transmission across synapses by speci . $^{-}$ humoral agents, of the isolation of these chemicalso leading to the terms 'cholinergic' and 'adrent-을 ergic,' of the application of the same principles roo sensory perception and central nervous transmissiog. Throughout the study has led to the discarding $f_{1}$ basic generalizations and long-standing concepts $=$. 잉

This volume, introduced by Dale, leads to the study of paradoxes; how injury does not necessarilyo terminate function, but may even elicit new ands previously unrelated nervous activities; how the same chemical transmitter acting on (apparently) exactly similar target organs can produce opposing $\mathbb{Q}$ and opposite effects; how even the same trans mitter can on the same organ give opposing effects; how the 'apocrine' sweat glands of the horse are adrenergic and respond to adrenaline even when no sympathetic or parasympathetic nerves reach them. Evidence is presented of sympathomimetic amineso being present in the brain, of the action of auto 3 . nomic transmitters in the brain, in the sensorro nervous system and in the motor end plate. The chemical mechanism of catechols in this process is studied deeply. Without saying further it is adequate to emphasize that the quality of authorshipo is proportional to the quality and originality of the work.

A.K.W.H.

BROMPTON HOSPITAL REPORTS: VOLUME: Pp. viii +312 , illustrated. London: Lloyd-Luke Ltd. 1957. I5s.

The latest volume of the Brompton Hospitalo 